\title{
Novel accelerated testing method for III-V concentrator solar cells
}

\author{
N. Núñez , M. Vázquez , J.R. González , C. Algora , P. Espinet \\ Instituto de Eneıgía Solar - Universidad Politécanica de Madrid, Madrid, Spain \\ EUITT - Universidad Politécnica de Madrid, Madrid, Spain
}

\begin{abstract}
A B S T R A C T
Accelerated testing is a necessary tool in order to demonstrate the reliability of concentration photovoltaic solar cells, devices which is expected to be working not less than 25 years. Many problems arise when implementing high temperature accelerated testing in this kind of solar cells, because the high light irradiation level, at which they work, is very dificult to achieve inside a climatic chamber. This paper presents a novel accelerated testing method for concentrator solar cells, under simulated electrical working conditions (i.e. forward biasing the solar cells at the equivalent current they would handle at 700 suns), that overcomes some of the limitations found in test these devices inside the chamber. The tracked power of the solar cells to $700 \times$, experiences a degradation of $1.69 \%$ after $4232 \mathrm{~h}$, in the $130^{\circ} \mathrm{C}$ test, and of $2.20 \%$ after $2000 \mathrm{~h}$ in the $150^{\circ} \mathrm{C}$ one. An additional test has been carried out at $150^{\circ} \mathrm{C}$, increasing the current to that equivalent to 1050 suns. This last test shows a power degradation of $4 \%$ for the same time.
\end{abstract}

\section{Introduction}

In the last years there has been an increase in the interest for Concentrator Photovoltaic (CPV) systems, both from the commercial and scientific point of view. If this technology is to be competjtive with conventional silicon flat modules, it is essential to offer similar warranties (i.e. 25 years). For doing so, it is important to carry out reliability testing in which the failure mechanisms as well as the power degradation with time are identified.

The aforementioned interest in CPV technology can be highlighted in the following points:

- Significant advances have been made in the field of [l]-V highconcentrator solar cells, achieving peak efficiencies of $32.6 \%$ at 1000 suns for a double junction solar cell [1] and of $41.6 \%$ at 236 suns for a triple-junction solar cel] [2].

- Several companies have set up manufacturing facilities, taking a step forward from CPV prototypes to industrial products, achieving an aggregate production capacity greater than 100 MW/year [3].

- The photovoltaic community has developed a new qualification standard the IEC62108 (CPV modules and assemblies - Design qualification and type approva]) [4]. In this standard, the procedure for qualifying CPV systems is described in the similar way that the IEC61215 for silicon flat modules [5].
However, there is no standard for doing the same with concentrator bare solar cells. Also there is not a standard that defines limit failure of power degradation, although any power degradation will imply economical losses.

The experience in concentrator cells reliability tests is scarce and has been mainly aimed at the assessment of their degradation [6,7]. As far as we know, the first accelerated thermal ageing test carried out to evaluate the reliability of concentrator solar cells in simulated working conditions, taking into account the power evolution with time, can be found in [8], in that work the arbitrary definition of failure will be a $10 \%$ of power loss. The tests presented here continue with the previous work and introduces relevant improvements taking advantage of the knowledge acquired in the first one.

The main problem when dealing with accelerated tests for concentrator solar cells is how to illuminate them inside a climatic chamber without limitations. For the sake of simplicity, the two main options will be highlighted:

1. Concentrate the light over each cell by introducing an optical fibre inside the climatic chamber. The problem of using a laser as a light source is that they are very expensive and they are not designed for being used during a long period of time. Besides, in the case of triple-junction solar cells, three lasers should be used for testing each one of them. Another option is the use of a concentration solar simulator, but these devices are still under development [9].

2. The use of solar cells inside a concentrator. This way the optics of the concentrator can be used to increase the light intensity to the working one. In this case only a continuous xenon lamp 
could be used, but the illuminated area is smaller. Besides, to take this option into consideration, a special climatic chamber with a transparent wall is required.

Because of all these limitations, this paper proposes a novel accelerated test methodology for CPV solar cells, with the aim of assessing the power degradation of this devices and this way gain insight into their reliability. This methodology has been applied in two long-term tests: $130^{\circ} \mathrm{C}$ test that have finished and $150^{\circ} \mathrm{C}$ that is on going.

\section{Test methodology}

It is important to point out that CPV solar cells work within a concentration range from 200 to 2000 times the solar irradiance $\left(1000 \mathrm{~W} / \mathrm{m}^{2}\right)$. To get such an illumination inside a climatic chamber is a really hard to solve problem. The proposed methodology to carry out accelerated test has three different parts:

- The working conditions of the solar cells have been simulated by forward biasing them at the same current level they would handle at the working concentration.

- In this test, the acceleration is due to a temperature stress. However, other stresses could be used with the same methodology.

- The generated power of every solar has been evaluated inside the climatic chamber by assessing the evolution of the $I-V$ curve measured in darkness (hereinafter, dark $I-V$ curve) and following a method based on a one diode model for the solar cell whose full description can be found in [10]. The maximum power obtained from the $I-V$ curve under concentrated illumination and the one obtained from the reproduced curve are within a $5 \%$ of difference [8].

The main stressor of devices with similar technology to that of concentrator solar cells, such as III-V semiconductor LEDs and lasers, are both the current density and the associated high temperature [11]. The current density of concentrator solar cells under illumination circulates through the whole active area. However, in this test, forward biasing the cells, the current circulates mainly vertically beneath the bus bar of the solar cell perimeter [12]. The current density has been calculated for the active area in nominal working conditions, and this value, taking the bus bar area into account, is the one used to forward bias the cells in this test.

\section{Experiment}

The test has been carried out over GaAs single junction solar cells, but the protocols defined here can be easily applied to other CPV solar cells. The two groups of solar cells under test have been mounted in 18 cells circuits using Direct Bonded Copper (DBC) substrates, which are in turn attached with thermal silicone to an aluminium box to maintain a very good thermal conductivity. Cells were coated with solar silicone, to protect the perimeter area, whose degradation was the cause of power loss in the previous test [8], and simulate the real solar a secondary optic. The nominal working temperature of the junction solar cell in the CPV system is $65^{\circ} \mathrm{C}$.

The active area of the cell is $1.318 \mathrm{~mm}^{2}$ and the bus bar area is $0.64 \mathrm{~mm}^{2}$. Taking into account that the current is injected through the bus bar, in order to keep cells working at 700 suns, a value of $112 \mathrm{~mA}$ has been selected, for reach a concentration of $1050 \times$, cells have been biased at $168 \mathrm{~mA}$.

In the first test, $130^{\circ} \mathrm{C}$, only cells without current injection and one working condition $700 \times$ have been tested. But in the second circuit, test at $150^{\circ} \mathrm{C}$, three conditions have been tested, cells without current injection and two working conditions, $700 \times$ and $1050 \times$.

The power evolution of each solar cell has been periodically evaluated with high precision, because the measurement of the dark $I-V$ curve is repetitive and has been carried out under stable and controllable conditions.

The system records the ambient temperature near the solar cell circuit in each dark $I-V$ curve measurement cell. All electrical measurements have been carried out using the 4 -wire method. A voltage ramp, from higher to lower values, with $14 \mathrm{mV}$ steps has been programmed to register the dark $I-V$ curves. Power losses for every solar cell have been evaluated comparing the measured dark $I-V$ curves with the initial one measured at the test temperature. The total power losses has been checked with the same process for initial and final dark $I-V$ curves measured at $65^{\circ} \mathrm{C}$ and at $25^{\circ} \mathrm{C}$.

\section{Results}

Two different stresses have been applied to the solar cells: working simulated conditions with current injection and temperature. In order to analyze the current injection influence in cells junction temperature we have measured junction temperature of each solar cell and evaluated it by means of 3D finite elements thermal simulations. Junction temperature has been evaluated inside the climatic chamber by means of the voltage-temperature characteristics in the diode forward I-V curve [13]. Due to the good thermal conductivity of the material for encapsulation under the chip and the high convection of the climatic chamber, the difference between temperature of cells without current injection and cells to $1050 \times$ is in the range of $2^{\circ} \mathrm{C}$. This result has been supported by the thermal simulations. Therefore thermal and current injection analysis can be done separately.

Main results of the tests can be summarized as follows:

1. No catastrophic failures have occurred in any solar cell. It implies that reliability analysis must consider solar cell degradation. Degradation tests results are shown in Table 1.

2. There are three different stages in the degradation evolution with time, Fig. 1:

Table 1

Power degradation at different temperature and concentration.

\begin{tabular}{llll}
\hline Temperature $\left({ }^{\circ} \mathrm{C}\right)$ & Time $(\mathrm{h})$ & $700 \times(\%)$ & $1050 \times(\%)$ \\
\hline 130 & 4232 & 1.69 & No tested \\
150 & 2000 & 2.20 & 4.0 \\
\hline
\end{tabular}

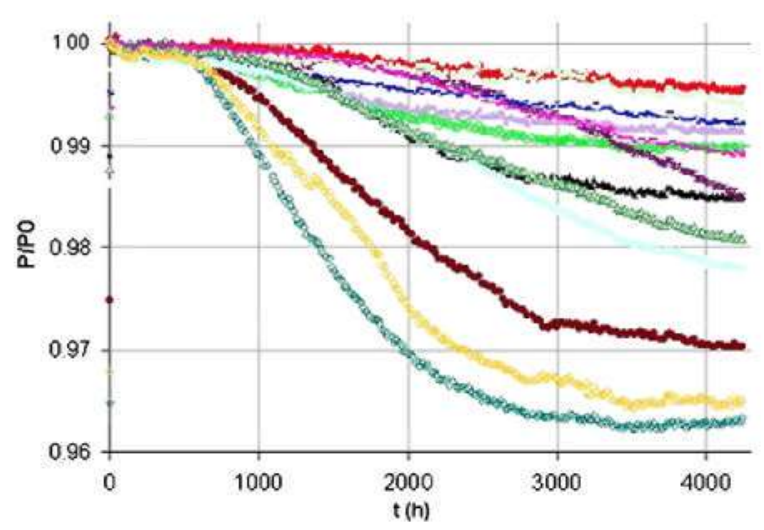

Fig. 1. Average cells relative power evolution at $130^{\circ} \mathrm{C}$ and $150^{\circ} \mathrm{C}$. $t$ _test $130^{\circ} \mathrm{C}$ is $130^{\circ} \mathrm{C}$ test time. 


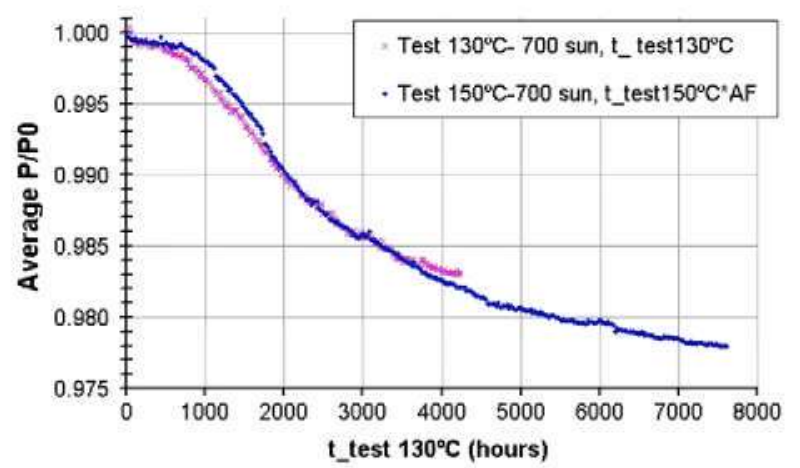

Fig. 2. Evolution of relative power of the cells at $130^{\circ} \mathrm{C}$.

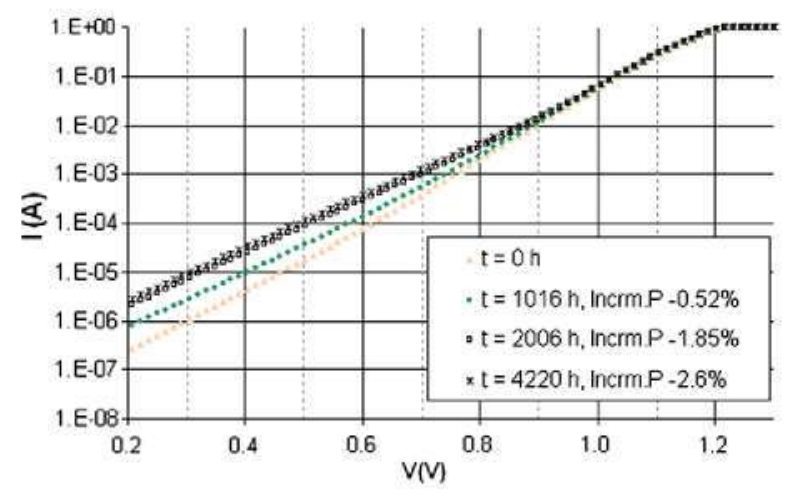

Fig. 3. Evolution power degradation of cell 8 dark $I-V$ curve $130^{\circ} \mathrm{C}$ test to $700 \times$.

During the first $600 \mathrm{~h}$ (at $130^{\circ} \mathrm{C}$ test) power degradation is almost negligible.

After that power degrades quicker showing wide dispersion for the different solar cells.

At the end the acceleration of degradation is reduced significantly. In this stage the power degradation with time has been analyzed by means of Weibull distribution observing that the acceleration is lower than for the exponential power degradation case.

3. The different value of current injection in cells for simulating working electrical conditions affects in an important way to power degradation. Solar cells at high temperature without current injection suffer a negligible degradation. The degradation in solar cells working at $1050 \times$ is two times higher than cells working at $700 \times$.

4. Temperature also affects to degradation. Preliminary results of the test at $700 \times$ shows, at $150^{\circ} \mathrm{C}$, and acceleration factor (AF) 3.8 times higher than at $130^{\circ} \mathrm{C}$. In Fig. 2 , the time of the test at $150^{\circ} \mathrm{C}$ test has been multiplied by this acceleration factor, fitting both degradation curves.

5. The degradation is much lower than in previous test [8] comparing the results to $150^{\circ} \mathrm{C}$. Therefore, the coated perimeter seems to be a good way for enhancing the performance.

6. In Fig. 3 we can see that the degradation of the dark $I-V$ curve is at low voltages range. To determine the degradation mechanism, a simulation of the dark $I-V$ curve using a computational 3D model method based on distributed circuital units has been done [14]. This analysis reveals that the degradation takes place in the perimeter region since the recombination current density in depletion region at the perimeter increases a factor 4 .

\section{Discussion}

All this analysis has been carried out in high concentration solar cells, with a high ratio perimeter-active area, and the results can be extrapolates to similar devices. The accelerated test method can also be applied to other types of concentration solar cells.

Related with the two stress parameters of the accelerated tests it is possible to remark:

1. The preliminary quantification of an acceleration factor time to different temperatures indicate that solar cells temperature working condition in the CPV system is critical to evaluate if the technology is competitive in degradation and reliability with conventional solar cells. These tests have been done in small area CPV cells, with easier thermal dissipation than large CPV cells. These large cells will need more careful thermal design.

2. Although the degradation at $1050 \times$ is two times higher than at $700 \times$, this degradation is only a $4 \%$ at $150{ }^{\circ} \mathrm{C}$ with a trend to stabilize. It means that these solar cells can work at this high concentration rate without important performance degradation.

The coated of the perimeter has improved significantly the reliability of the cells, because reduce the perimeter degradation.

\section{Conclusions}

Temperature and simulated electrical working conditions accelerated tests have been carried out in high concentrator CPV solar cells. Main conclusions of these tests are:

- Power degradation is the unique failure mechanism observed in all the tests.

- Power degradation in coated CPV solar cells trend to stabilize, improving significantly degradation in uncoated cells.

- Temperature and current injection influence in degradation has been analyzed, proving that this type of cell can work at high concentration level.

- The experiment is still ongoing with the objective of getting the MTTF, and $R(t)$ function. For doing so it is necessary to analyze the power evolution at other temperatures in order to validate the Arrhenius law.

The methodology presented in this work allows the development of accelerated tests for CPV cells inside a climatic chamber. This testing will be soon extended to multijunction solar cells.

\section{Acknowledgements}

This work has been supported by the Spanish Ministerio de Educación y Ciencia with the CONSOLIDER-INGENIO 2010 program by means of the GENESIS FV project (CSD2006-004). The Spanish Ministerio de Ciencia e Innovación has also contributed with the SIGMASOLES project (PSS-440000-2009-30) and with the project with reference TEC2008-01226 as well as the Comunidad de Madrid under the NUMANCIA II programme (S2009/ENE1477).

\section{References}

[1] Algora C, Rey-Stolle 1, García I, Galiana B, Espinet P, Baudrit M, et al. A dual junction solar cell with an efficiency of $32.6 \%$ at 1000 suns and $31.0 \%$ at 3000 suns. In: 5th International conference for the generation of electricity, palm desert; November 2008.

[2] King $R$, et al. Band-gap-engineered architectures for high-efficiency multijunction concentrator solar cells. In: 24th European photovoltaic solar energy conference and exhibition, Hamburg; September 2009.

[3] Kurtz S. Opportunities and challenges for development of a mature concentrating photovoltaic power industry. NREL/TP-520-43208; November 2009.

[4] IEC 62108: Concentrator photovoltaic (CPV) modules and assemblies - design qualification and type approval. 
|5| JEC 61215: Crystalline silicon terrestrial photovoltaic (PV) modules - design qualification and type approval.

|6| Rey-Stolle 1. Algora C. Reliabilicy and degradation of high concentrator GaA solar cells. In: Proceedings of the 17th European photovoltaic solar energy conference; 2001.

|7| Araki K, et al. Development of a new $550 \times$ concentrator module with 3] cellsperformance and reliability. In: Proceeding 31st JEEE photovoltaic specialist conference; 2005.

[8] González JR, Vázquez M, Núñez N, Algora C, Rey-Stolle I, Galiana B. Reliability analysis of temperature step-stress tests on III- $V$ higl concentrator solar cells. Microelectron Reliab 2009;49:673-80.

[9] Domínguez C, Antón I, Sala G. Solar simulator for concentrador photovoltaic systems. Opt Express 2008;16(19)
[10] Antón ], Sala G. Heasman K, Kern R, Bruton TM. Performance prediction of concentrator solar cells and modules from dark I-V characteristics. Prog Photovolt: Res Appl 2003:11:165-78.

[11] Meneghini M, Trevisanello L, Sanna C, Mura G, Vanzi M, Meneghesso G, et al. Higl temperature electro-optical degradation of $\ln \mathrm{GaN} / \mathrm{GaN} \mathrm{HBLEDs}$. Microelectron Reliab 2007:47:1625-9.

[12] Galiana B, Algora C, Rey-Stolle I. Explanation for the dark I-V curve of III-V concentrator solar cells. Prog Photovolt: Res Appl 2008;16.

[13] Zhao LX, Thrush EJ, Humphreys CJ. Degradation of GaN-based quantum well light-enitting diodes. J Appl Plys 2008; 103:024501.

|14| Espinet P. Algora C, González JR, Núinez N, Vázquez M. Analysis of degradation mechanisms in temperature stress test of Il]-V concentrator solar by a $3 \mathrm{D}$ distributed model. ESREF 2010. 